\title{
A GIS study of dioxin contamination in a Vietnamese region sprayed with herbicide
}

\author{
Dang Duc Nhu $\cdot$ Teruhiko Kido $\cdot$ Rie Naganuma $\cdot$ Nobuhiro Sawano \\ Kenji Tawara $\cdot$ Muneko Nishijo $\cdot$ Hideaki Nakagawa $\cdot$ Nguyen Ngoc Hung $\cdot$ \\ Le Thi Hong Thom
}

Received: 23 January 2009/Accepted: 5 August 2009/Published online: 1 September 2009

(C) The Japanese Society for Hygiene 2009

\begin{abstract}
Objectives The American-Vietnam War ended over 35 years ago, but dioxins still remain in human tissue and Vietnam's environment. The main objective of this study was to assess the correlation between dioxin concentration in soil, sediment and breast milk in one of the areas sprayed with herbicide, namely Cam Chinh commune, Quang Tri province, using a geographic information system (GIS).

Methods The concentration of polychlorinated dibenzop-dioxins (PCDDs) and polychlorinated dibenzofurans (PCDFs) in soil, sediment and breast milk samples was determined and the data analyzed using the geostatistical log-normal Kriging algorithm.

Results The mean dioxin levels in soil and breast milk in the sprayed area were significantly higher than those in the
\end{abstract}

D. D. Nhu $(\bowtie) \cdot$ T. Kido $\cdot$ R. Naganuma

Division of Health Sciences, Graduate School of Medical

Science, Kanazawa University, 5-11-80 Kodatsuno,

Kanazawa, Ishikawa 920-0942, Japan

e-mail: dangnhu258@yahoo.com

N. Sawano

Seiryo Women's Junior College, Tori-1,

Goshomachi, Kanazawa, Ishikawa 920-0813, Japan

K. Tawara

Department of Public Health, Hyogo College of Medicine, 1-1 Mukogawa, Nishinomiya, Hyogo 663-8501, Japan

M. Nishijo · H. Nakagawa

Department of Epidemiology and Public Health,

Kanazawa Medical University, 1-1 Daigaku, Uchinada,

Ishikawa 920-0293, Japan

N. N. Hung · L. T. H. Thom

10-80 Division, Hanoi Medical University,

35 Nguyen Huy Tuong, Thanh Xuan, Hanoi, Vietnam non-sprayed area. The distribution pattern of PCDDs and PCDFs in soil was different, and there were no significant correlations between the estimated dioxin levels in soil obtained by the Kriging method and those in breast milk. Conclusions The possibility remains that another exposure route, such as exposure to herbicides used during the Vietnam War, might affect dioxin levels in breast milk, although more soil data are needed to make more reliable geographical estimations.

Keywords Agent Orange · Dioxin · GIS · Kriging · Vietnam

\section{Introduction}

During the Vietnam War (1961-1971), the United States military carried out an operation code-named Ranch Hand that involved spraying over 19.5 million gallons of herbicide onto the land to defoliate large areas of forest and crops in Vietnam, Laos and Cambodia in order to deny their use by opposition forces [1, 2]. Agent Orange, a 50:50 mixture of the herbicides 2,4,5-trichlorophenoxyacetic acid (2,4,5-T) and 2,4-dichlorophenoxyacetic acid (2,4-D), accounted for two-thirds of the herbicides used [3]. The defoliant 2,4,5-T was, however, contaminated with an extremely toxic substance, namely 2,3,7,8-tetrachlorodibenzo-p-dioxin (TCDD), which is known to have adverse effects on human health.

The Vietnam War ended over 35 years ago, but herbicide residues are still producing adverse effects in people who lived in the sprayed areas and on the country's ecosystems [4-7]. In environmental health research, there is a recognized need to develop methodologies to carry out epidemiological research. A geographic information 
system (GIS) is one way of improving the study of dioxins in Vietnam in order to estimate people's herbicide exposure. A GIS can also combine both extensive and intensive databases on the dispersal of herbicides, the location of US army military units and bases, and the location of civilian population centers in Vietnam, thereby providing a unique basis for the integration and improvement of epidemiological studies [8-10]. GIS-based exposure assessment in epidemiological studies of the environment is still relatively uncommon [11] despite the fact that it can efficiently integrate records of where herbicides were used.

The results of investigations at a sprayed site, namely the ALuoi Valley in southern Vietnam, demonstrate the apparent food-chain transfer of TCDD from contaminated soil to cultured fish pond sediments, then on to fish and duck tissues, and finally to humans, as measured in whole blood and breast milk [12]. The ALuoi Valley is considered to be representative of southern Vietnam as a whole, where the soils have been contaminated by numerous TCDD reservoirs [12]. Dwernychuk et al. [12], for example, have proposed a model for the remobilization of Agent Orange dioxin into humans in Vietnam whereby the dioxin present in soil and sediment is taken up by farm animals after initial incorporation into duck and fish tissue. Humans then take up the dioxin upon consumption of animals reared in contaminated duck and fish ponds, with the subsequent effects on human health.

There have been numerous studies worldwide and in Vietnam concerning the effects of dioxin on the environment and human health $[5,7,12]$. However, most of these studies are somewhat limited as regards study subjects, sample size and study method, and some of them encountered difficulties when undertaking the chemical analysis, etc. In addition, very few studies have applied a GIS to the study of dioxin levels in soil and breast milk in Vietnam. The main objective of this study was therefore to determine the correlation between dioxin concentration in soil, sediment and breast milk in Cam Chinh commune, Quang Tri province.

\section{Materials and methods}

\section{Study area}

This study was implemented in two areas: one where herbicides were sprayed and one where they were not sprayed. An area sprayed with herbicide in Cam Chinh commune, Quang Tri province, was chosen as the case site. Quang Tri province was sprayed with herbicide 150 times at a rate of 6,602 1/ha [13, 14]. Quang Tri borders the demilitarized zone along the 17th parallel that once divided North from South Vietnam. The control site was Cam Phuc commune in Ha Tinh province, which was not sprayed with herbicide during the war.

Estimation of the spatial distribution of polychlorinated dibenzodioxins (PCDDs) and polychlorinated dibenzofurans (PCDFs)

The spatial distribution of PCDD/Fs was estimated by the Kriging interpolation method from 16 soil samples and one sediment sample. Kriging, which presents mathematical modes of a spatial phenomenon based on a continuous possibility field, was originally developed to estimate the distribution of mineral deposits and is widely used to create a curved response surface. Several different methods can be used during Kriging interpolation [15]; however, Saito et al. [16] have reported that the "log-normal Kriging" method consistently yields the best results for dioxin concentration.

The Kriging interpolator is a specialized interpolation method that assumes the distance or direction between sample points and shows their spatial correlation, which helps to describe the surface [17]. Initially, breast milk samples were collected from lactating females aged between 20 and 40 years of age at Quang Tri in 20022003; these samples were analyzed at the Kanazawa Medical University, Japan. The location of all these women's homes was verified by GPS (Global Positioning System). The GPS data were coded in terms of latitude (Y) and longitude $(\mathrm{X})$ and the position of the houses located on the map (Fig. 1). Soil and sediment samples were taken from the same area (Fig. 1) and also analyzed in the Japanese laboratory. These data were used to create a surface contour of dioxin for this area using the Geostatistical Analyst program, one of the extension systems of ArcGIS.

\section{Soil and sediment samples}

The soil and sediment samples were taken randomly throughout Cam Chinh commune. Sixteen soil samples and one sediment sample were collected with a stainless-steel core sampler at a depth of $0-10 \mathrm{~cm}$ [12]. Ten cores were collected at each site, then combined and thoroughly mixed to produce a single sample for laboratory analysis. The location of each sample was referenced as above by GPS. The location of the sampling sites is shown in Fig. 1.

Breast milk samples

Breast milk samples were taken from lactating mothers aged between 20 and 40 years of age, living in two communes, between September 2002 and July 2003. The purpose of the study was explained to the 86 lactating mothers in Cam Chinh commune and the 71 lactating mothers in 
Fig. 1 Overlaid GPS data for breast-milk, soil and sediment samples in Cam Chinh. The primary agent used (about $65 \%$ of the herbicides) was called Agent Orange, which was a 50:50 mixture of 2,4-D and 2,4,5-T. Agent Orange was only one of several herbicide mixtures used during Operation Ranch Hand during the Vietnam War. Lesser amounts of Agent Purple (2,4-D and 2,4,5-T), Pink (2,4,5-T), Green $(2,4,5-\mathrm{T})$, white (2,4-D plus picloram) and Blue (caccodylic acid) were applied. The 2,4,5-T in Agents Purple, Pink, Green and Orange was, unfortunately, contaminated with varying levels of dioxins [2]

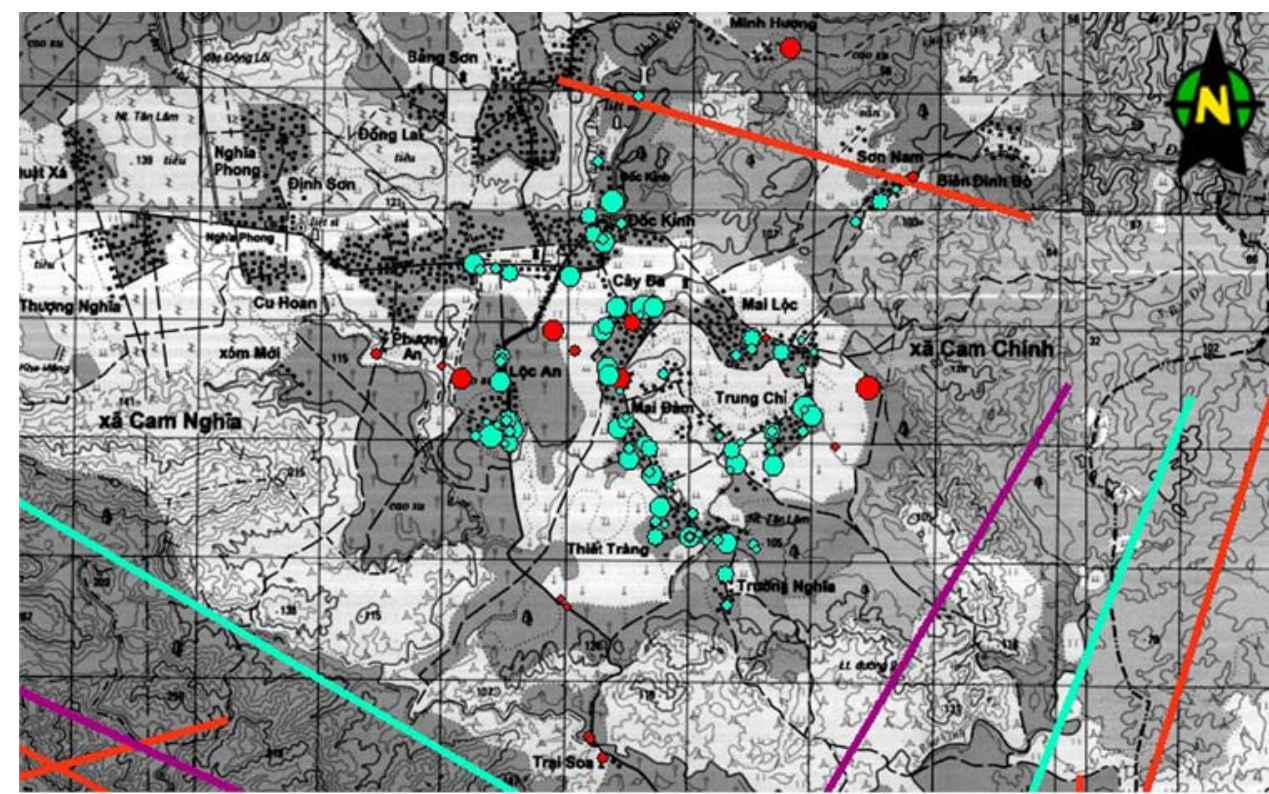

Legend

The location of soil and sediment sample sites in Cam Chinh commune

- The residence of mothers who has taken Breast milk samples

Agent Orange spray mission paths

- Agent White spray mission paths

- Other Agent spray mission paths
Cam Phuc commune by local authorities and medical staff. In the sprayed area, 64 mothers lived in Cam Chinh commune, and 12 were born in Cam Nghia commune but moved to Cam Chinh commune after marriage. Cam Nghia commune is near Cam Chinh commune and was also sprayed during the war. In the non-sprayed area, 71 mothers lived in Cam Phuc commune. All lactating mothers consented to donate milk samples. The mothers were breastfeeding infants aged from 20 days to 1 year and provided $10-20 \mathrm{ml}$ of milk. Samples were collected by the mothers themselves and local medical staff at each local clinic and were frozen immediately after collection.

\section{Survey method}

A retrospective cohort survey, based on epidemiological interviewing, was implemented. All lactating mothers in each commune who donated milk samples were interviewed directly by researchers of the 10-80 Division and Kanazawa University using a standard questionnaire to acquire information. The information collected included personal habits such as smoking, alcohol drinking, contraceptive drug use, history of pesticide contact, disease history, number of pregnancies, age at each pregnancy and reason for pregnancy failure, if applicable. All data were analyzed using the $\mathrm{JMP}^{\circledR} 6$ software package.

Analytical method

Statistical comparisons were made using the chi-square and Wilcoxon signed rank tests for categorical variables and the Turkey-Kramer HSD test for continuous variables $(\alpha=0.05$ level). Odds ratios (OR) and 95\% confidence intervals (95\% CI) based on the chi-square and Wilcoxon signed rank tests were calculated on the basis of epidemiological data.

All soil and sediment samples were frozen and sent to the Ishikawa Prefecture Institute of Public Health and Environmental Science for analysis using previously described methods [18, 19]. Breast milk samples were analyzed at the Center for High Technology at the Kanazawa Medical University, Japan. ${ }^{13} \mathrm{C}$-labeled surrogate standards were added to each sample prior to analysis. All extracts were subjected to a series of chromatographic cleanup steps prior to analysis on a high resolution mass spectrometer (HRGC/HRMS, JMS-700 MStation, JEOL, 
Japan) equipped with a gas chromatograph (HP-6980); data were obtained using the selected ion monitoring (SIM) method $[20,21]$. The dioxin concentrations obtained were converted into 2,3,7,8-TCDD toxic equivalents (TEQ) using the international WHO Toxicity Equivalent Factors (TEFs) from 1997 [22] and 2005 [23]. Non-detectable (ND) and NDR (chromatographic peak detected but did not meet quantification criteria) data were not rejected.

Maps representing the study's findings were generated using ArcGIS. The database was merged into the GIS software using the Kriging interpolation method for geostatistical analysis [24, 25]. The distribution of dioxin contamination was estimated from the soil samples. The dioxin levels in the soil of each woman's house were estimated, and the relationship between this value and that determined in breast milk was analyzed using the Kriging method.

\section{Ethics}

This study was approved by the Kanazawa University Medical Ethics Committee (Permission no. Health-89). Written informed consent was obtained from each subject via their local people's authority committee. All data were coded during the analysis, and no individuals were identified.

\section{Results}

The mean concentration of dioxin in soil in the sprayed area was $1.9 \mathrm{pg}-\mathrm{TEQ} / \mathrm{gI}$, a significantly higher value than that obtained for the non-sprayed area $(0.38 \mathrm{pg}-\mathrm{TEQ} / \mathrm{g})$.

The reproductive cohort survey on mothers was carried out in two communes, with 86 mothers from the area sprayed with herbicide and 71 from the non-sprayed area. The results in Table 1 show that the mean dioxin level in breast milk in the sprayed area was significantly $(p<0.001)$ higher than in the non-sprayed area. A statistically significant difference was determined for the mothers' mean height and weight between the sprayed and non-sprayed areas (both values were lower in the sprayed area), although the difference in BMIs was not significant. The number of mothers who had used pesticides was significantly higher in the non-sprayed area than in the sprayed area $(p<0.001)$, although differences in the use of other chemicals are not significant between the two areas. None of the mothers drank alcohol, whereas three mothers in the sprayed area smoked $(3.6 \%)$. The difference between the number of women with cousins born with birth defects in the sprayed area $(15.2 \%)$ and the non-sprayed area $(10.6 \%)$ was not significant. The number of mothers currently suffering from a disease was significantly higher in the sprayed area $(22.1 \%)$ than in the non-sprayed area $(8.6 \%, p<0.05)$, as was the history of reproductive failure $(22.1 \%$ in the sprayed area and $5.6 \%$ in the non-sprayed area, $p<0.01)$.

This study aimed to assess the correlation between dioxin levels in soil and those in breast milk of females in Cam Chinh commune, Quang Tri province, Vietnam. One of the GIS technologies of the Kriging interpolation method was used to check the correlation, although this gave values of only $r=0.02$ for PCDDs and $r=0.03$ for PCDFs (Figs. 2, 3).

In addition, we also found that the distribution of PCDDs and PCDFs in soils obtained by the Kriging interpolation analysis was quite different. Thus, the Kriging map for PCDDs shows no correlation between dioxin levels in soil and those in breast milk (Fig. 2). The red points in Fig. 4 indicate the dioxin levels in soil and the blue points the dioxin levels in breast milk. The larger red points (high dioxin level) are surrounded by dark colors, whereas the smaller red points (low dioxin level) are surrounded by lighter colors.

Likewise our results show no correlation between PCDFs and dioxin levels in soil and breast milk (Fig. 3). As in Fig. 4, the red points on the Kriging map for PCDFs (Fig. 5) indicate dioxin levels in soil and the blue points dioxin levels in breast milk. However, the location of the red points is different from those in Fig. 4, and the dark color is also different: in this case it is not around the high dioxin levels in soil.

\section{Discussion}

Nearly 40 years have elapsed since Operation Ranch Hand, and the indigenous people who inhabit Cam Chinh commune remain a relatively isolated population that experiences little inward or outward migration. This region is a valley with no industry; therefore, its inhabitants subsist as an agrarian society raising vegetables, rice, peppercorn, poultry, some livestock and fish. They eat almost exclusively homegrown food.

The soil dioxin levels in our study were lower in "hot spot" areas, such as Bien Hoa and ALuoi [4, 7, 12], although the levels were higher in the sprayed area than in the non-sprayed area. As the non-sprayed area was not subject to defoliation, very little dioxin exposure would have occurred there. Schecter et al. [4] have reported that TCDD levels were higher in the blood of 19 out of 20 persons living on a site contaminated with Agent Orange, namely Bien Hoa in southern Vietnam. The TCDD levels in these subjects, one of whom had a level of $271 \mathrm{ppt}$, were 135-times higher than in people living in non-contaminated areas in northern Vietnam. Another study has been 
Table 1 Comparison of characteristics and dioxin levels in breast milk of mothers from regions sprayed and not sprayed with herbicide

\begin{tabular}{|c|c|c|c|c|c|}
\hline & \multicolumn{2}{|c|}{ Sprayed area } & \multicolumn{2}{|c|}{ Non-sprayed area } & \multirow[t]{2}{*}{$p$ value } \\
\hline & No. & Mean \pm SD or $n o .(\%)$ & $N$ & Mean $\pm \mathrm{SD}$ or $N(\%)$ & \\
\hline Age (years) & 86 & $29.3 \pm 5.7$ & 71 & $26.1 \pm 4.3$ & $* * * \mathrm{a}$ \\
\hline Height (cm) & 79 & $152.4 \pm 4.6$ & 54 & $154.1 \pm 5.5$ & $*^{\mathrm{a}}$ \\
\hline Weight (kg) & 85 & $43.6 \pm 3.9$ & 66 & $45.8 \pm 4.0$ & $* *^{\mathrm{a}}$ \\
\hline BMI $\left(\mathrm{kg} / \mathrm{m}^{2}\right)$ & 78 & $18.8 \pm 1.5$ & 54 & $19.4 \pm 1.8$ & n.s. ${ }^{\mathrm{a}}$ \\
\hline \multicolumn{6}{|l|}{ Contact with herbicides during the war } \\
\hline Yes & & $4(4.9 \%)$ & 71 & $0(\%)$ & - \\
\hline No & 82 & $71(86.6 \%)$ & & $71(100 \%)$ & \\
\hline Do not know & & $7(8.5 \%)$ & & $0(\%)$ & \\
\hline \multicolumn{6}{|l|}{ Uses pesticides } \\
\hline Yes & 82 & $7(8.5 \%)$ & 68 & $31(45.6 \%)$ & $* * * \mathrm{~b}$ \\
\hline \multicolumn{6}{|l|}{ Uses other chemicals } \\
\hline Yes & 84 & $2(2.4 \%)$ & 65 & $0(\%)$ & - \\
\hline \multicolumn{6}{|l|}{ Alcohol habit } \\
\hline Yes & 83 & $83\left(100^{\circ} \%\right)$ & 69 & $69(100 \%)$ & - \\
\hline \multicolumn{6}{|l|}{ Smoke status } \\
\hline Yes & 83 & $3(3.6 \%)$ & 71 & $0(\%)$ & - \\
\hline \multicolumn{6}{|l|}{ Uses contraceptives } \\
\hline Yes & 80 & $3(3.8 \%)$ & 65 & $1(1.5 \%)$ & n.s. ${ }^{b}$ \\
\hline \multicolumn{6}{|l|}{ Women with cousin born with birth defect } \\
\hline Yes & 79 & $12(15.2 \%)$ & 66 & $7(10.6 \%)$ & n.s. ${ }^{b}$ \\
\hline The number of cousins born with birth defects (people) & 12 & $1.3 \pm 0.9$ & 7 & $1 \pm 0$ & n.s. ${ }^{\mathrm{a}}$ \\
\hline \multicolumn{6}{|l|}{ Present disease } \\
\hline Yes & 86 & $19(22.1 \%)$ & 70 & $6(8.6 \%)$ & $* \mathrm{~b}$ \\
\hline \multicolumn{6}{|l|}{ History of reproductive failure } \\
\hline Yes & 86 & $19(22.1 \%)$ & 71 & $4(5.6 \%)$ & $* * \mathrm{~b}$ \\
\hline TEQ-PCDDs (pgTEQ/g fat) ${ }^{\mathrm{c}}$ & 86 & $5.1 \pm 3.2$ & 71 & $2.1 \pm 0.9$ & $* * * a$ \\
\hline TEQ-PCDFs (pgTEQ/g fat) ${ }^{\mathrm{c}}$ & 86 & $6 \pm 4$ & 71 & $2 \pm 0.8$ & $* * * \mathrm{a}$ \\
\hline TEQ-Total (pgTEQ/g fat $)^{\mathrm{c}}$ & 86 & $11.3 \pm 7$ & 71 & $4.2 \pm 1.6$ & $* * * \mathrm{a}$ \\
\hline
\end{tabular}

a Wilcoxon signed rank test. $* * * p<0.001$

b Chi-square

${ }^{c}$ Dioxin levels data were log-transformed

$* p<0.05 ; * * p<0.01 ; * * * p<0.001$, n.s., not significant

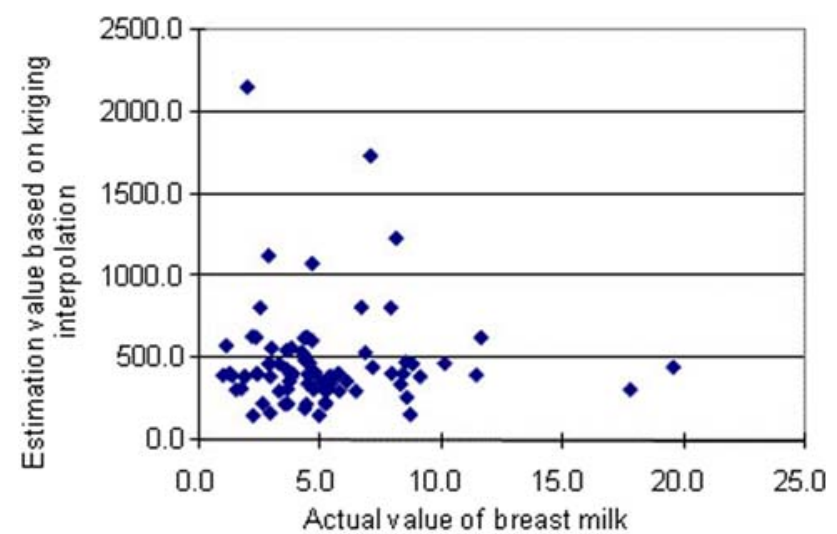

Fig. 2 The relationship between estimated values in soil obtained by the Kriging method and those actually in breast milk for PCDDs

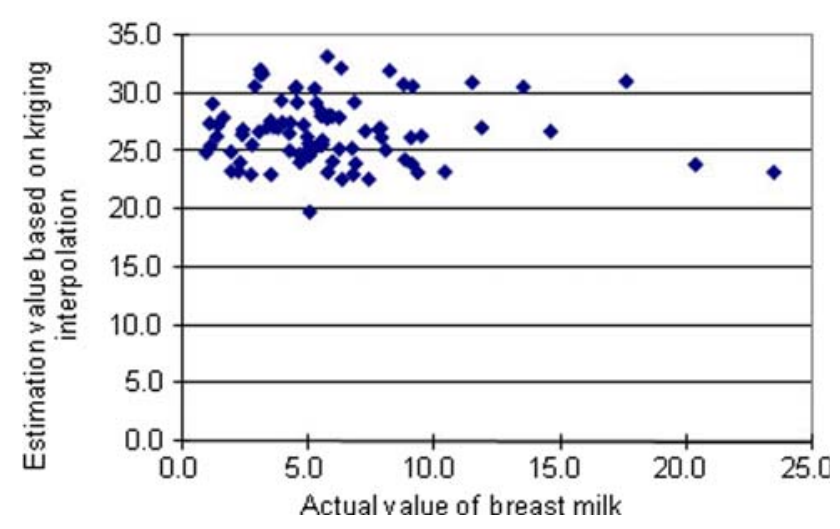

Fig. 3 The relationship between estimated values in soil obtained by the Kriging method and those actually in breast milk for PCDFs 
Fig. 4 Estimated distribution of PCDDs from soil samples by the Kriging method

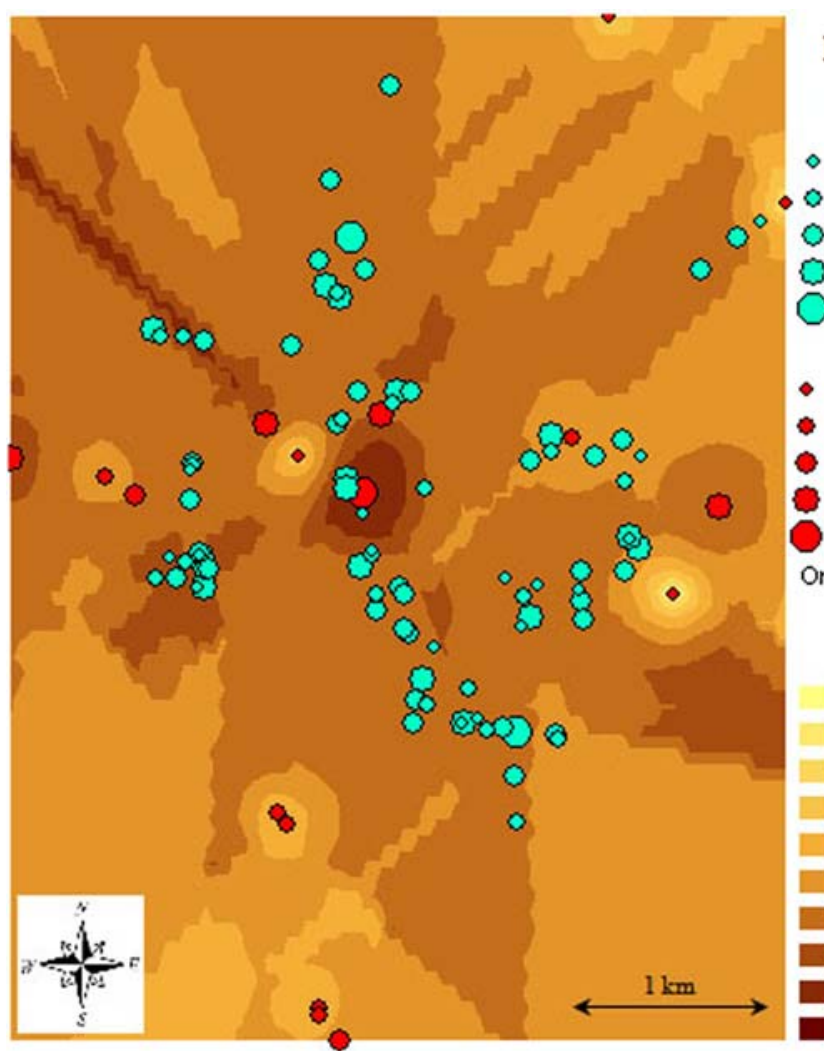

\section{Legend}

PCDDs in breast milk (pg/g fat)

$0.99-2.63$

$2.63-4.26$

$4.26-6.88$

$6.88-11.67$

$11.67-19.63$

PCDDs in soil and sed (pg/g soil, sed)

- $33.60-67.50$

- $67.51-143.00$

- $143.01-279.30$

$279.31-578.00$

$578.01-3332.10$

Ordinary Kriging

Prediction Map

[PCDO] (pg/g soil, sed)

$33.60-51.27$

$51.27-60.60$

$60.60-78.27$

$78.27-111.77$

$111.77-175.29$

$175.29-295.69$

$295.69-523.95$

$523.95-956.67$

$956.67-1776.99$

$1776.99-3332.10$
Fig. 5 Estimated distribution of PCDFs from soil samples by the Kriging method

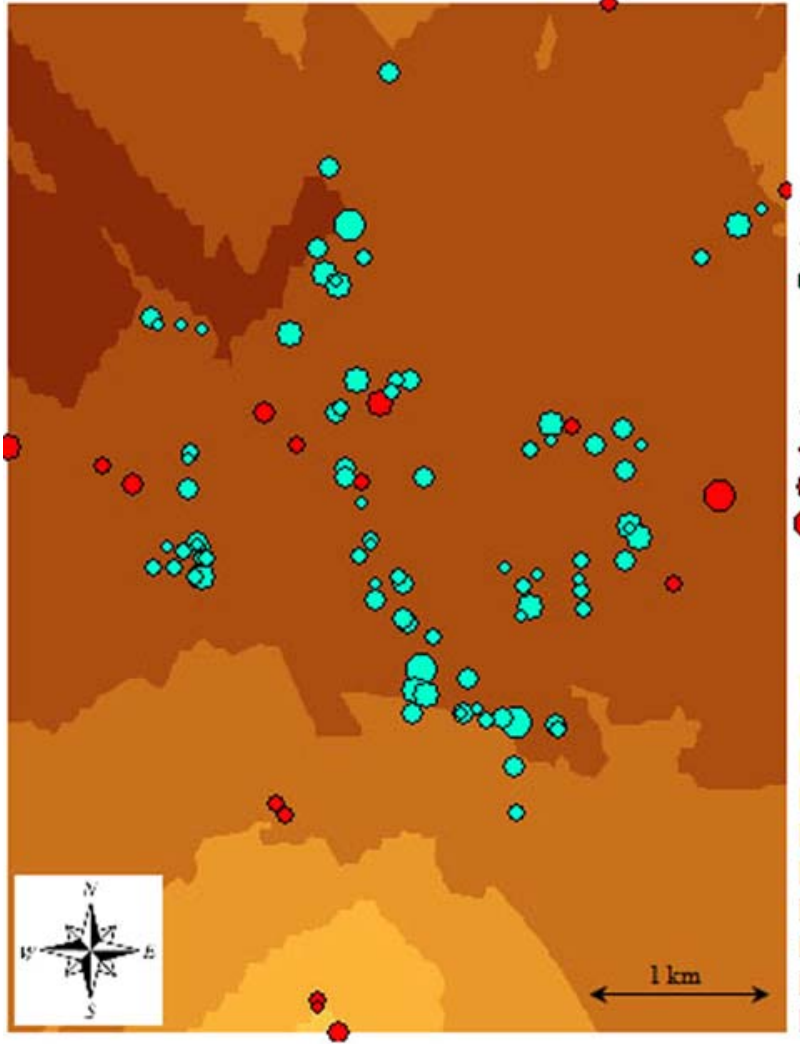

\section{Legend}

PCDFs in breast milk (pg/g fat)

- $0.94-3.19$

- $3.19-5.32$

$5.32-8.24$

$8.24-14.65$

$14.65-23.53$

PCDFs in soil and sed (pg/g soil, sed)

- 1.49

- $1.50-15.20$

- $15.21-38.00$

$38.01-61.00$

$61.01-81.50$

Ordinary Kriging

Prediction Map

[PCDF] (pg/g soil, sed)

$1.49-6.98$

$6.98-10.05$

$10.05-11.77$

$11.77-12.73$

$12.73-14.45$

$14.45-17.52$

- $17.52-23.01$

$23.01-32.80$

$\square 32.80-50.29$

$50.29-81.50$ 
undertaken recently to detect dioxin hot spots in provinces in southern Vietnam. The results of this study showed that dioxin contamination in soil and sediment is higher than normal and identified specific US bases as hot spots (797 pg/g TCDD in Bien Hoa, 227 pg/g TCDD in Da Nang and $194 \mathrm{pg} / \mathrm{g}$ TCDD in Phu Cat) [26, 27].

Several studies in regions of southern Vietnam where herbicide was used have shown that dioxin levels in human breast milk have decreased with time, falling from 333$1,850 \mathrm{pg} / \mathrm{g}$ lipid in 1970 , to $77-400 \mathrm{pg} / \mathrm{g}$ lipid in 1973, and 5.2-11 pg/g lipid in 1985-1988. The levels in northern Vietnam were lower, with breast milk from Hanoi having a mean dioxin concentration of $2.1 \mathrm{pg} / \mathrm{g}$ lipid in 1988 [4, 28]. The values reported herein for dioxin levels in breast milk in 2002 and 2003 are similar to those found in the 1980s.

In 2001, a Japanese medical research team initiated a study concerning the human impact of herbicide spraying. This study has consistently found significantly higher dioxins levels in serum, breast milk and adipose tissue in inhabitants of sprayed areas (Quang Tri province) than those in non-sprayed areas (Ha Tinh province), although no significant difference was found as regards early indicators of adverse health effects, such as liver or thyroid function and immunological activities [29]. Similarly, Kido et al. [30] have shown that the visual acuity of both eyes for people in sprayed areas was significantly lower than those in non-sprayed areas at every condition with change of contrast from 100 to $2.5 \%$ except for $2.5 \%$ contrast of the left eye. The simple relationships between dioxin levels and visual acuity were shown as mild in both eyes.

One of the main reasons why we were unable to find a correlation is likely to be the length of time that has passed since the end of the war. The half-life for dioxin elimination by the human body, for example, is estimated to be 7-11 years [31, 32] and that for soil is 28.5-274 years [33]. A second reason could be the rather low number of samples (16 for soil, 1 for sediment and 86 for breast milk). In contrast, the lack of a significant relationship could also mean that the present environmental status, as represented by soil dioxin levels, is not consistent with human exposure, as represented by levels in breast milk. The possibility therefore remains that another exposure route, such as exposure to herbicides during the Vietnam War, might affect the dioxin levels in breast milk.

The large difference in PCDD and PCDF distributions in soil and sediment has been analyzed by Kriging interpolation. The PCDDs were thought to come from Agent Orange, which was sprayed in the Quang Tri area in 19651970 [34], whereas the PCDFs in this area are thought to come from herbicides other than Agent Orange that were sprayed during the war, along with other chemicals and pesticides applied after the war.
The reasons why we cannot detect a clear correlation between dioxin levels in soil and breast milk therefore include: (1) the length of time that has passed since the war, (2) the biased alignment of soil samples and (3) the fact that a larger area needs to be tested to account for people's immigration tendencies. More studies will therefore be required to obtain a larger number of soil samples, which should be well-distributed throughout the study site, including dioxin hot spots.

The concentrations of PCDDs and PCDFs in soil, sediment and breast milk samples collected in one of the Vietnamese regions sprayed with herbicide, namely Cam Chinh commune, Quang Tri, have been determined to assess correlations using geostatistic algorithms and the log-normal Kriging method. The results of this study show that mean dioxin levels in soil and breast milk in the sprayed area are significantly higher than in the nonsprayed area. However, there were no significant correlations between the estimated dioxin levels in soil and those in breast milk. This suggests the possibility that another exposure route, such as exposure to herbicides during the Vietnam War, may be responsible for the dioxin levels in breast milk. The distribution patterns of PCDDs and PCDFs are also quite different. More soil data are therefore needed to be able to make more reliable geographical estimations.

Acknowledgments This study was supported by grants from the Japan Society for the Promotion of Science [Grant-in-Aid for Scientific Research, (B) no. 17406016 and Grant-in-Aid for Scientific Research (A) no. 19209021] and the Yoshida Scholarship Foundation, Japan. The authors would like to thank Dr. Wayne Dwernychuk at Hatfield Consultants in Vancouver, Canada, and officers of the 10-80 Division, Hanoi Medical University, Vietnam, for making this study possible.

\section{References}

1. Westing AH. Herbicides in war: the long-term ecological and human consequences. London: Taylor and Francis; 1984. p. 3-24.

2. Stellman JM, Stellman SD, Christian R, Weber T, Tomassalo C. The extent and patterns of usage of Agent Orange and other herbicides in Viet Nam. Nature. 2003;422:681-7.

3. IOM (Institute of Medicine). Veterans and Agent Orange-health effects of herbicides used in Viet Nam. Washington, D.C: National Academy Press; 2002.

4. Schecter A, Dai LC, Papke O, Prange J, Constable JD, Matsuda $\mathrm{M}$, et al. Recent dioxin contamination from Agent Orange in residents of a Southern Vietnam city. J Occup Environ Med. 2001;43:435-43.

5. Schecter A, Quynh HT, Papke O, Malisch R, Constable JD, Tung KC. Halogenated organics in Vietnamese and in Vietnam food: dioxin, dibenzofurans, $\mathrm{PCBs}$, polybrominated diphenyl ethers and selected pesticides. J Occup Environ Med. 2003;45:781-8.

6. Cau HD. Environment and human health in Vietnam: thirty years after the Ranch Hand Operation, Hanoi, 10-80 Committee; 2003. 
7. Mai TA, Doan TV, Tarradellas J, de Alencastro LF, Grandjean D. Dioxin contamination in soils of Southern Vietnam. Chemosphere. 2007;67:1802-7.

8. Stellman JM, Stellman SD, Weber T, Tomasallo C, Stellman AB, Christian R. A geographic information system for characterizing exposure to Agent Orange and other herbicides in Vietnam. Environ Health Perspect. 2003;111:321-8.

9. Waring SC, Zakos-Feliberti A, Wood R, Stone M, Padgett P, Arafat R. The utility of geographic information systems (GIS) in rapid epidemiological assessments following weather-related disasters: methodological issues based on the Tropical Storm Allison experience. Int J Hyg Environ Health. 2005;208:109-16.

10. Viel JF, Clément MC, Hägi M, Grandjean S, Challier B, Danzon A. Dioxin emissions from a municipal solid waste incinerator and risk of invasive breast cancer: a population-based case-control study with GIS-derived exposure. Int J Health Geogr. 2008;7:4.

11. Rushton G. Public health, GIS, and spatial analytic tools. Annu Rev Public Health. 2003;24:43-56.

12. Dwernychuk LW, Cau HD, Hatfield CT, Boivin TG, Hung TM, Dung PT, et al. Dioxin reservoirs in southern Viet Nam-a legacy of Agent Orange. Chemosphere. 2002;47:117-37.

13. 10-80 Committee. Herbicides Sprayed Map; 1999.

14. Vietnam Investment Review, Ministry of Planning and Investment, Socialist Republic of Vietnam. War border province's Agent Orange tragedy. Issue: 0410; 1999.

15. Armstrong M, Boufassa A. Comparing the robustness of Ordinary Kriging and Lognormal Kriging: outlier resistance. Math Geol. 1988;20:447-57.

16. Saito H, Goovaerts P. Geostatistical interpolation of positively skewed and censored data in a dioxin contaminated site. Environ Sci Technol. 2000;34:4228-35.

17. Largueche FB. Estimating soil contamination with Kriging interpolation method. Am J of Appl Sci. 2006;3:1894-8.

18. Kakimoto H, Oka H, Harada Y, Ushijima S, Toriba A, Kizu R, et al. Comparison of compositions of polychlorinated-dibenzop-dioxins (PCDDs) and dibenzofurans (PCDFs) in air and soil samples collected in Ishikawa. J Health Sci. 2004;50:58-65.

19. Oka H, Miyakawa S, Noguchi K, Watanuki F, Tsukabayashi H, Yada M. Dioxin levels in soil and sediment of Vietnam. J Ishikawa Prefect Inst Public Health Environ Sci. 2007;44:7981. (in Japanese).

20. Tawara K, Honda R, Nishijo M, Nakagawa H. Pretreatment procedure of dioxin analysis for a small volume of human breast milk. J Kanazawa Med Univ. 2003;28:17-25. (in Japanese).

21. Nishijo M, Tawara K, Nakagawa H, Honda R, Kido T, Nishijo H, et al. 2, 3, 7, 8-Tetrachlorodibenzo-p-dioxin in maternal breast milk and newborn head circumference. J Expo Sci Environ Epidemiol. 2008;18:246-51.
22. Van den Berg M, Birnbaum L, Bosveld ATC, Brunstrom B, Cook $\mathrm{P}$, Feeley M, et al. Toxic equivalency factors (TEFs) for PCBs, PCDDs, PCDFs for humans and wildlife. Environ Health Perspect. 1998;106:775-92.

23. Van den Berg M, Birnbaum L, Denison M, De Vito M, Farland W, Feeley M, et al. The 2005 World Health Organization re-evaluation of human and mammalian toxic equivalency factors for dioxins and dioxin-like compounds. Toxicol Sci. 2006; 93:223-41.

24. Cattle JA, McBratney AB, Minasny B. Kriging method evaluation for assessing the spatial distribution of urban soil lead contamination. J Environ Qual. 2002;31:1576-88.

25. Wu J, Norvell WA, Hopkins DG, Smith DB, Ulmer MG, Welch RM. Improved prediction and mapping of soil copper by Kriging with auxiliary data for cation-exchange capacity. Soil Sci Soc Am J. 2003;67:919-27.

26. Dwernychuk LW. Dioxin hot spots in Vietnam. Chemosphere. 2005;60:998-9.

27. Dwernychuk LW, Hung TM, Boivin TC, Bruce GS, Dung PT, Son TK, et al. The Agent Orange dioxin issue in Vietnam: a manageable problem. Organohalogen Compd. 2006;68:312-5.

28. Schecter A, Ryan JJ, Papke O. Decrease in levels and body burden of dioxins, dibenzofurans, PCBs, DDE, and HCB in blood and milk in a mother nursing twins over a 38 month period. Chemosphere. 1998;37:1807-16.

29. Tawara K, Nishijo M, Nakagawa H, Kido T, Naganuma R, Hung $\mathrm{TM}$, et al. Areal differences of concentration levels of polychlorinated dibenzo-p-dioxins and dibenzofurans in human breast milk from Vietnam and Japan. Organohalogen Compd. 2006; 68:1655-8.

30. Kido T, Suzuki H, Naganuma R, Tawara K, Nishijo M, Nakagawa $\mathrm{H}$, et al. An epidemiological study on health effects by dioxin in Vietnam; comparison of contrast acuity between inhabitants of herbicide sprayed and non-sprayed areas. The 26th International Symposium on Halogenated Persistent Organic Pollutants. Organohalogen Compd. 2006;68:1990-3.

31. Mukerjee D. Health impact of polychlorinated dibenzo-p-dioxins: a critical review. J Air Waste Manag Assoc. 1998;48:157-65.

32. Kerger BD, Leung HW, Scott PK, Paustenbach DJ. An adaptable internal dose dodel for risk assessment of dietary and soil dioxin exposures in young children. Toxicol Sci. 2007;100:224-37.

33. Sinkkonen S, Paasivirta J. Degradation half-life times of PCDDs, PCDFs and PCBs for environmental fate modeling. Chemosphere. 2000;40:943-9.

34. IOM (Institute of Medicine). Veterans and Agent OrangeHealth effects of herbicides used in Viet Nam. Washington, D.C: National Sciences Academy Press; 1998. 